\title{
Editorial
}

\section{e Aspirin-Inspired Analgesia: Old Drug, New Mechanism, Sans Cox?}

Howard S. Smith, MD

$\square$ or many centuries it has been appreciated that willow bark possesses medicinal effects. Its active component, salicylate, has a number of potentially beneficial effects, but perhaps most notable are its anti-inflammatory and analgesic effects. Aspirin and salsalate are rapidly metabolized in the plasma (e.g., plasma esterases), erythrocyte, and liver, to salicylate in vivo (1).

Hippocrates, considered by some to be the father of modern medicine ( 460 B.C.-377 B.C.), reportedly left historical records of pain relief treatments, including the use of powder from the bark and leaves of the willow tree to help heal headaches, pains, and fevers. In 1826, 2 Italians, Brugnatelli and Fontana, extracted a highly impure form of the active chemical substance of willow bark. Two years later, Johann Buchner isolated a very small amount of bitter tasting yellow crystals that he called salcin. A year later French chemist Henri Leroux extracted salcin in crystalline form with a much improved procedure, yielding about 30 grams from $1.5 \mathrm{~kg}$ of bark. In 1838 , Raffaele Piria split salcin into a sugar and an aromatic compound, salicylaldehyde. He then converted salicylaldehyde by hydrolysis and oxidation to an acid (in its pure state) called salicylic acid. In 1853, in an effort to make this compound less irritating to the gastric mucosa, Charles Frederick Gerhardt neutralized salicylic acid by buffering it with sodium (sodium salicylate) and acetyl chloride, producing acetylsalicylic acid, but he later abandoned the compound.

Maclagan (2) utilized salcin, the bitter principal of the common white willow, in an effort to diminish the pain and inflammation of rheumatic fever. Arthur Eichengrün, the head of Bayer Research Laboratories, assigned Felix Hoffman to develop a compound which was safer and more effective than salicylic acid. Hoffman rediscovered Gerhardt's work and synthesized acetylsalicylic acid. Heinrich Dreser, Bayer's chief pharmacologist, tested the new compound and described its analgesic and antipyretic effects, giving it the name aspirin (3). Aspirin was patented on February 27, 1900. For 71 years aspirin's mechanism of action remained unknown, until John Vane revealed that it inhibited the synthesis of prostaglandins (4).

As for anti-inflammatory effects, it has likely been correctly postulated that aspirin and salicylate produce anti-inflammatory inhibition of cyclo-oxygenases and thus, prostanoid synthesis (5) and also protein kinase IkBkinase $\beta$ (IKK $\beta$ ) in the NF-kB pathway (6). However, these are not necessarily the most likely mechanisms for other effects from salicylate since some of these salicylate-induced effects are still observed in mice that are deficient in these pathways (7).

Aspirin may also contribute to antinociception via: activation of adenosine $A(2)$ receptors (8), inhibiting the inhibitor of NF-kB (IkB) kinase $\beta$ (thereby preventing translocation of NF-kB) to the nucleus (9); inhibition of sphingosine-1-phosphate generation (10); inhibition of $\alpha, \beta$-methylene ATP-induced nociception (11); inhibition of acid-sending ion channels (with high doses of aspirin) (12); acetylation of COX-2 leading to aspirin-triggered lipoxins (e.g., 15-epi-LX A4) (13); promotion of aspirin-triggered DHA pathway (e.g., neuroprotectin D1/protectin D1 which is $10 \mathrm{R}, 17 \mathrm{R}$-dihydroxydocosa-4Z, 7Z, 11E,

From: Albany Medical College, Albany, NY;

Dr. Smith is Editor-in-Chief of Pain Physician, Professor \& Academic Director of Pain Management, Albany Medical College, Albany, New York. E-mail: smithh@mail.amc.edu

Disclaimer: There was no external funding in the preparation of this manuscript. Conflict of interest: None. 
13E, 15Z, 19Z-hexaenoic acid) (14). Resolvins (and likely resolving-like compounds) derived from DHA appear to possess antinociceptive properties (15-18).

Smith (19) has postulated still another potential mechanism that could conceivably contribute to the antinociceptive actions of aspirin-induced analgesia. He proposes that aspirin may contribute to nociception via a salicylate-induced activation of AMP Kinase (19). AMP kinase (AMPK) is a serine/ threonine protein kinase that serves as a metabolic sensor and helps regulate a cell's energy balance, shifting cellular efforts toward generating more ATP when stores run low, suggesting that activation of the energy-sensing AMP kinase may underlie some of aspirin's health benefits (20). Salicylate has been found to activate AMP kinase when applied to human embryonic kidney (HEK) 293 cells with significant effects at ImM and above (21), as well as activate AMP kinase in colorectal cancer cell lines (20). Hawley and colleagues (21) found results suggesting that salicylate can directly activate AMPK, likely primarily by inhibiting dephosphorylation of the activating phosphylation site, threonine-172. In AMPK knockout mice, the effects of salicylate to increase fat utilization and to lower plasma fatty acids in vivo were lost. These results suggest that AMPK activation could explain some beneficial effects of salsalate and aspirin in humans (21).

AMP kinase can also be activated by stress and exercise as well as metformin, thiazolidinediones resveratrol, (-)-epigallocatechin-3-gallate (EGCG), and A-769622 (22-24). Preclinical models have demonstrated that activation of AMP kinase appears to produce antinociception, in part likely via attenuation of ERK and mTOR signaling in sensory neurons $(24,25)$. AMP kinase activation may lead to diminished inhibited translational regulation signaling, modulation of eukaryotic initation factor (elF)4F complex formation, and reduced nascent protein synthesis in injured nerves with resultant antinociceptive effects (25).

Even if there is any validity to this proposed mechanism for aspirin-induced analgesia (AIA), it is likely only a part of the AIA story But if modulation of AMP kinase activity contributes at all, or plays any role in AIA, it may open up the potential for novel analgesic targets.

\section{References}

1. Williams FM. Clinical significance of esterases in man. Clin Pharmacokinet 1985; 10:392-403.

2. Maclagan TJ. The treatment of acute rheumatism by salicin. Lancet 1876 ; i:342-383.

3. Dreser H. Pharmacologisches über Aspirin (Acetylsalicyl-saüre). Pflügers Arch Gesamte Physiol Menschen Tiere 1899; 76:306-318.

4. Vane JR. Inhibition of prostaglandin synthesis as a mechanism of action for the aspirin-like drugs. Nature 1971; 231:232-235.

5. Higgs GA, Moncada S, Vane JR. Eicosanoids in inflammation. Ann Clin Res 1984; 16:278-299.

6. Yuan M, Konstantopoulos N, Lee J, Hansen L, Li ZW, Karin M, Shoelson SE. Reversal of obesity- and diet-induced insulin resistance with salicylates or targeted disruption of Ikkbeta. Science 2001; 293:1673-1677.

7. Cronstein BN, Montesinos MC, Weissmann G. Salicylates and sulfasalazine, but not glucocorticoids, inhibit leukocyte accumulation by an adenosine-dependent mechanism that is independent of inhibition of prostaglandin synthesis and p105 of NFkappaB. Proc Natl
Acad Sci USA 1999; 96:6377-6381.

8. Cronstein BN, Montesinos MC, Weissmann $G$. Sites of action for future therapy: An adenosine-dependent mechanism by which aspirin retains its anti-inflammatory activity in cyclooxygenase-2 and NFkappaB knockout mice. Osteoarthritis Cartilage 1999; 7:361-363.

9. Yin MJ, Yamamoto Y, Gaynor RB. The anti-inflammatory agents aspirin and salicylate inhibit the activity of I(kappa)B kinase-beta. Nature 1998; 396:77-80.

10. Ulrych T, Böhm A, Polzin A, Daum G, Nüsing RM, Geisslinger G, Hohlfeld T, Schrör K, Rauch BH. Release of sphingosine-1-phosphate from human platelets is dependent on thromboxane formation. J Thromb Haemost 2011; 9:790-798.

11. Ristic D, Spangenberg P, Ellrich J. Acetylsalicylic acid inhibits 0,0-meATPinduced facilitation of neck muscle nociception in mice-implications for acute treatment of tension-type headache. Eur J Pharmacol 2001; 673:13-19.

12. Wang W, Ye SD, Zhou KQ, Wu LM, Huang YN. High doses of salicylate and aspirin are inhibitory on acid-sensing ion channels and protective against acidosis-induced neuronal injury in the rat cortical neuron. J Neurosci Res 2012;
90:267-277.

13. Clària J, Serhan CN. Aspirin triggers previously undescribed bioactive eicosanoids by human endothelial cell-leukocyte interactions. Proc Natl Acad Sci U S A 1995; 92:9475-9479.

14. Serhan CN, Fredman G, Yang R, Karamnov S, Belayev LS, Bazan NG, Zhu M, Winkler JW, Petasis NA. Novel proresolving aspirin-triggered DHA pathway. Chem Biol 2011; 18:976-987.

15. Xu ZZ, Zhang L, Liu T, Park JY, Berta T, Yang R, Serhan CN, Ji RR. Resolvins $\mathrm{RvEl}$ and RvDl attenuate inflammatory pain via central and peripheral actions. Nat Med 2010; 16:592-597.

16. Ji RR, Xu RR, Strichartz G, Serhan CN. Emerging roles of resolvins in the resolution of inflammation and pain. Trends Neurosci 2011; 34:599-609

17. Park CK, Xu ZZ, Liu T, Lü N, Serhan $C N$, Ji RR. Resolvin D2 is a potent endogenous inhibitor for transient receptor potential subtype $V_{1} / A_{l}$, inflammatory pain, and spinal cord synaptic plasticity in mice: Distinct roles of resolvin D1, D2, and E1. J Neurosci 2011; 31:1843318438.

18. Huang L, Wang CF, Serhan CN, Strichartz $\mathrm{G}$. Enduring prevention and tran- 
sient reduction of postoperative pain by intrathecal resolvin D1. Pain 2011; 152:557-565.

19. Smith HS. Novel mechanisms of A agents. Presented at Capital District Pain Meeting; May 2012; Albany, NY.

20. Din FV, Valanciute A, Houde V, Zibrova D, Green KA, Sakamoto K, Alessi DR, Dunlop MG. Aspirin Inhibits mTor Signaling, Activates AMP-Activated Protein Kinase, and Induces Autophagy in Colorectal Cancer Cells. Gastroenterology 2012; In Press.

21. Hawley SA, Fullerton MD, Ross FA, Schertzer JD, Chevtzoff C, Walker KJ, Peggie MW, Zibrova D, Green KA, Mustard KJ, Kemp BE, Sakamoto K, Stein- berg GR, Hardie DG. The ancient drug salicylate directly activates AMP-activated protein kinase. Science 2012; 336:918922.

22. Davis BJ, Xie Z, Viollet B, Zou MH. Activation of the AMP-activated kinase by antidiabetes drug metformin stimulates nitric oxide synthesis in vivo by promoting the association of heat shock protein 90 and endothelial nitric oxide synthase. Diabetes 2006; 55:496-505.

23. Collins QF, Liu HY, Pi J, Liu Z, Quon $M J$, Cao W. Epigallocatechin-3-gallate (EGCG), a green tea polyphenol, suppresses hepatic gluconeogenesis through 5'-AMP-activated protein kinase. J Biol Chem 2007; 282:30143-30149.
24. Tillu DV, Melemedjian OK, Asiedu MN, Qu N, De Felice M, Dussor G, Price T). Resveratrol engages AMPK to attenuate ERK and mTOR signaling in sensory neurons and inhibits incision-induced acute and chronic pain. Mol Pain 2012; 8:5.

25. Melemedjian OK, Asiedu MN, Tillu DV, Sanoja R, Yan J, Lark A, Khoutorsky A, Johnson J, Peebles KA, Lepow T, Sonenberg N, Dussor G, Price TJ. Targeting adenosine monophosphate-activated protein kinase (AMPK) in preclinical models reveals a potential mechanism for the treatment of neuropathic pain. Mol Pain 2011; 7:70. 
